\title{
Editorials
}

\section{Food labels for consumers, motivated or otherwise}

The battle over the design of front-of-package (FOP) food labelling continues. Last October, the US Institute of Medicine (IOM) issued a report recommending a simple plan $^{(1)}$ : FOP labels would show zero to three stars depending on the presence of added sugars, sodium and saturated or trans fats in the product. Foods with excessive amounts of any one of those nutrients would receive no stars. The food industry intends to continue following its own plan, in which FOP labels show amounts per serving of energy, saturated fat, sodium and sugars, but potentially also up to two 'nutrients to encourage, (2). In a previous report, the IOM had recommended that FOP labelling exclude 'good' nutrients and emphasize only the negative ones, for an unambiguous message ${ }^{(3)}$. The message, essentially, should be this: either 'This is bad for you' or 'This is not bad for you'. It has been over 2 years since the US Food and Drug Administration announced that it would propose standards for FOP labelling. But if or when it will take any action on food labelling is unclear.

In this issue of Public Health Nutrition, Barker and colleagues offer a cautionary voice in the food labelling battle $^{(4)}$. We may argue over what information to put on the front of the package, but whether labelling even makes a measurable difference in dietary behaviour is still up in the air. Their invited editorial makes the point that food labels are not enough to produce behaviour change, particularly in the people who most need it. In an article by Chen et al. also in this issue, we see clearly who is not reading food labels men, black men in particular, women of low socio-economic standing, rural residents and overweight Americans who perceived their weight as being 'about right'(5). These are people who should be reading labels. Is it because they don't know how to use them, or because they know they won't use the information on them anyway?

Seen from this perspective, the IOM's recommendation of an unambiguous emphasis on negative nutrients makes perfect sense. For the consumer who doesn't know how to use the more confusing labels, a visually clear label should help. For the consumer who doesn't plan to use the information, FOP labels might work in a more subtle way - by giving the consumer pause; by planting the seed of knowledge, warning or guilt; by acting as the angel on the shoulder. The fact is that we don't need more encouragement to buy things that most of us know are good for us (hence the recommendation to exclude positive nutrients from labels). We need the little voice in our ear to remind us that something we're about to drop in our shopping cart is bad for us.
The study by Hieke and Wilczynski provides some evidence for this ${ }^{(6)}$. In their evaluation of consumers' responses to a traffic light scheme of labelling, participants paid greater attention to a change from 'amber' to 'red' compared with a change from 'green' to 'amber'. A red light delivers the unambiguous message of danger to consumers motivated enough to look for the information. It may also deliver the necessary reminder - the knowledge, warning or guilt - for people not looking for it.

In another article in this issue, McLean et al. describe a more specific application of food labelling for discriminating between high- and low-sodium products, and they confirm the utility of a traffic light system in delivering the necessary information clearly and simply ${ }^{(7)}$. Turconi et al. address a separate but related topic of providing nutrition information in a cafeteria setting ${ }^{(8)}$. In their study, customers perceived information on meals' nutritional content as very helpful and most claimed to have changed their decision after knowing the foods' nutritional content.

It is notable that several of the articles we highlight here raise the issue of empowerment: consumers should be empowered to use food labels, to make informed decisions, to take control over their health behaviours and, hence, their health status. But whether food labels work in such a noble fashion or whether they are just a subtle way of delivering a subliminal message does not ultimately matter - all we really want is for them to work.

Agneta Yngve Editor-in-Chief

Irja Haapala Allison Hodge Geraldine McNeill Marilyn Tseng Deputy Editors

\section{References}

1. Neuman W (2011) Label plan offered to rate food nutrition. The New York Times, 20 October; available at http://www. nytimes.com/2011/10/21/business/a-plan-to-rate-nutritionof-food-with-stars.html

2. Neuman W (2011) Food makers devise own labeling plan. The New York Times, 24 January; available at http:// www.nytimes.com/2011/01/25/business/25label.html?_r=1 \&adxnnl=1\&adxnnlx =1330524233-Wo/eOfGmgCeZFWf Dl8u5ow

3. Neuman W (2010) Group seeks food label that highlights harmful nutrients. The New York Times, 13 October; 
available at http://www.nytimes.com/2010/10/14/health/ nutrition/14label.html

4. Barker M, Lawrence W, Robinson S et al. (2012) Food labelling and dietary behaviour: bridging the gap (Invited Editorial). Public Health Nutr 15, 758-759.

5. Chen X, Jahns L, Gittelsohn J et al. (2012) Who is missing the message? Targeting strategies to increase food label use among US adults. Public Health Nutr 15, 760-772.

6. Hieke S \& Wilczynski P (2012) Colour Me In - an empirical study on consumer responses to the traffic light signposting system in nutrition labelling. Public Health Nutr $\mathbf{1 5}$, 773-782.

7. McLean R, Hoek J \& Hedderley D (2012) Effects of alternative label formats on choice of high- and lowsodium products in a New Zealand population sample. Public Health Nutr 15, 783-791.

8. Turconi G, Bazzano R, Roggi C et al. (2012) Helping consumers make a more conscious nutritional choice: acceptability of nutrition information at a cafeteria. Public Health Nutr 15, 792-801.

\section{Food labelling and dietary behaviour: bridging the gap}

A recent review in this journal demonstrated the unparalleled reach of nutrition labels on pre-packaged food as sources of nutrition information - more than half of people surveyed claim to read or use nutrition labels in some way ${ }^{(1)}$. Those who have campaigned for mandatory nutritional labelling in high-income countries across the world should now feel their efforts vindicated by the wide prevalence of label use and the consistent association of label use with healthier eating habits ${ }^{(1)}$.

However, this association is not necessarily causal. As the review we mentioned points out, it is as likely that individuals who already have healthier diets seek out and use food labels as it is that food labels themselves promote healthier eating. An illustration of the difficulty in connecting food labelling with behaviour change is the failure of the recent changes in US legislation, making it a legal requirement to post calorie information on the menus of chain restaurants, to reduce the calorie content of food purchased at these restaurants ${ }^{(2,3)}$. In an evaluation of a fascinating natural experiment, Elbel and colleagues compared fast-food purchases from restaurants in lowincome neighbourhoods in New York with those from restaurants in Newark, New Jersey, a city that had not at that time introduced menu labelling ${ }^{(2)}$. Despite nearly $28 \%$ of New York City respondents saying that they had not only noticed but been influenced by the calorie information, the research team found no difference in the overall energy content of foods purchased from restaurants in New York City and Newark, New Jersey. Dumanovsky and colleagues made a similar observation in their before-andafter comparison, showing no overall decline in calories purchased after regulations were introduced ${ }^{(3)}$. These findings have since been confirmed in a review of seven such studies ${ }^{(4)}$, and highlight the general gap between people's knowledge about what they need to do to keep healthy and how they behave.

There is plenty of evidence that people know what they should be eating to improve their health and reduce their body weight. For example, the first wave of the new survey 'Food and You', based on interviews with 3163 people over the age of 16 years around the UK, found that $99 \%$ of respondents rated eating fruit and vegetables, 94\% eating less salt and $92 \%$ limiting foods high in saturated fat as very or fairly important for a healthy lifestyle ${ }^{(5)}$. In addition, $84 \%$ of them knew that, of all food groups, they should be eating the smallest amount of foods high in fat and/or sugar. However, figures from the most recent National Diet and Nutrition Survey show that only $30 \%$ of adults in the UK currently consume the recommended amount of fruit and vegetables, and that mean intakes of saturated fats and non-milk extrinsic sugars exceed the recommendation that they provide no more than $11 \%$ of food energy ${ }^{(6)}$. The fact that people's diets do not reflect what they know to be healthy suggests that simply providing more information is not going to produce the population-level improvements in diet that we seek.

But there are approaches that evidence suggests will work in helping people make changes to their diets and, which furthermore, may work with the disadvantaged populations that have traditionally been difficult to reach with health promotion activities. One of these is an empowerment or patient-centred approach. In clinical settings, this way of working empowers patients to take control of their medical conditions, and become key decision makers in their care and treatment. Applications of a patient-centred approach have been associated with better outcomes, and disease self-management programmes, such as the Department of Health's 'Expert Patient' Programme, have been shown to be more effective than standard patient education in improving outcomes and quality of life for patients with chronic conditions ${ }^{(7,8)}$. The success of the empowerment approach in changing behaviour suggests that it may have application to improving health behaviour in the general population. The 'Health Trainer' initiative is one example of such an application ${ }^{(9)}$. Health trainers are recruited mainly from the community in which they work 